\title{
Some characteristics of sub-surface Irrigation tubes
}

\author{
Y. Shinogi \\ (Japan International Research Center for Agricultural Sciences)
}

\begin{abstract}
The author performed some tests to clarify some characteristics of sub-surface irrigation tubes.

The relationship between water discharge and pressure can be approximated by a square function, as in the case of sprinkler and drip tubes. Uniformity of water discharge from the tube is low, especially when under high pressures. For volcanic ash soil, water from the tube spread almost spherically. The water infiltration front spread over $0.25 \mathrm{~m}$ in about 2 days.

A model was made to simulate soil water movement of a sub-surface irrigation tube. The simulated results showed a good agreement with observed data.

Key words; Irrigation, Water management, Soil water movement.
\end{abstract}

\section{Introduction}

In arid and semi-arid regions, it is important to use water efficiently. Recently, a sub-surface irrigation tube was developed. When the tube is used, evaporation from the soil surface can be regulated and this is useful for saving water. In humid areas, it would be suitable to use the tube in a green house to regulate humidity.

In this research, some tests were performed to clarify the basic characteristics of the tube. In addition, a model was made to simulate soil water movement under irrigation by this tube.

\section{Methods}

1) Hydraulic test.

A hydraulic test was performed using the apparatus shown in Fig.1. To determine the uniformity of discharge from the tube, the test was performed on the soil surface. A $50 \mathrm{~m}$ long tube was set flatly over a side ditch. The height difference of the measurement location was less than $0.09 \mathrm{~m}$.

Water pressure at $10 \mathrm{~m}$ intervals was measured with a pressure gauge.

Discharged water was collected by $0.5 \mathrm{~m}$ long water gutters and measured by mess-cylinder. The captured time was 10 15 minutes.



Q:Flow meter, Pn:Pressure Gage

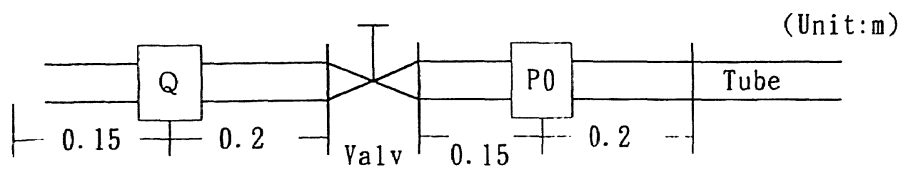

Fig.1 Irrigation test apparatus. 


\section{2) Irrigation test.}

Soil was packed in a transparent acrylic box $\left(0.5 \mathrm{~m}^{*} 0.75^{*} \mathrm{~m}^{*} 0.45 \mathrm{~m}\right)$ with a subsurface tube fixed at $0.3 \mathrm{~m}$ depth. The packed soil was air-dried volcanic ash soil, known as Kanto-loam. Soil water movement was investigated.

3) Outline of water movement model.

a)Model

A model was used to determine soil water movement from the tube. The model was constructed using a combination of Darcy's equation and mass conservation equation. The soil water movement could be represented with Eq.(1).

$$
\frac{\partial \theta}{\partial t}=\frac{\partial}{\partial z}\left\{\frac{\partial \psi m}{\partial z}-1\right\}
$$

Herein, $\theta$;Water content(Water content per volume)(\%),t;time(s),z;Depth (m),kz; Hydraulic conductivity $(\mathrm{m} / \mathrm{s}), \psi \mathrm{m}$; Suction $(\mathrm{kPa})$.

Eq.(1) was solved for the initial and boundary conditions shown in eq.(2) (4) by FEM methods. Mesh space was about $0.01 \sim 0.02 \mathrm{~m}$ and time interval was $60 \mathrm{~s}$.
I.C $; \psi \mathrm{m}=\psi 0(\mathrm{t}=0)$
B.C.; $\psi m \geq 0(t>0$, at soil surface $)$
B.C.; $q=Q 0$ (From tube)
$\psi 0$; Initial suction $(\mathrm{kPa}), \mathrm{q}, \mathrm{Q} 0$; Water discharge from tube $(\mathrm{m} / \mathrm{s})$.

b) Formulation of parameters in the model.

To determine the parameters in the model, the following tests were performed. At first, water holding characteristics were examined by soil column and pressure plate methods.

Next, unsaturated hydraulic conductivity was measured by the Bruce\&Klute method. A transparent acrylic cylinder (inner diameter $0.02 \mathrm{~m}$ ) was sliced into rings of $0.01 \mathrm{~m}$ and 15 pieces were connected to form a column. Air dried soil passed through a $0.002 \mathrm{~m}(2 \mathrm{~mm})$ sieve was packed into the column. The dry density of the soil sample was about $860\left(\mathrm{~kg} / \mathrm{m}^{3}\right)$ and water content was about $11 \sim 16 \%$ (air-dried). The time taken for the infiltration front to reach before the end was about 1,800 seconds.

To obtain the characteristics of evaporation from the soil surface, a test was performed. Soil packed cylinders $\left(0.0001 \mathrm{~m}^{3}\right)$, already settled at fixed state of the soil water suction with soil column and pressure plate method, were left in controlled growth chamber $\left(25^{\circ} \mathrm{C}\right.$ and $55 \%$ humidity) for one day. The relationship between evaporation from soil surface and soil water suction was obtained.

To obtain dimensionless evaporation, evaporation from the water surface was measured simultaneously with a small pan evaporimeter. Average evaporation from the water surface in the growth chamber was about $4.0 \mathrm{~mm} /$ day.

\section{Results and discussion}

1) Hydraulic characteristics 
Fig.2 shows the relationship between inlet pressure and water discharged from the tube. The square of the water discharged was proportional to inlet pressure. This relationship is similar to those of other irrigation facilities such as sprinkler and drip tubes.

Table 1 shows water pressure and irrigation discharge at each place. The friction loss was comparatively large in the tube. Water pressure and discharge were low at the end of the tube. The uniformity of water discharge was comparatively small, especially under high pressure.

However, it could be fairly uniform in soil due to the redistribution of water.

2) Formulation

a) Water retention curve

The water retention curve of the soil is shown in Fig.3. This relation is approximated by Eq.(5). $\psi \mathrm{m}=2.7 * 10^{-27} * \theta^{-15.2}$

b) Unsaturated hydraulic conductivity

The relationship between unsaturated hydraulic conductivity and soil water suction is shown in Fig.4. It decreases linearly with soil water suction. This relationship is represented by Eq.(6).

$$
\mathrm{kz}=1.14 * 10^{-5} * \exp (-1.11 * \psi \mathrm{m})
$$

c) Evaporation from soil surface.

The relationship between evaporation from the soil surface and soil water suction is shown in Fig.5. When there is abundant moisture, evaporation does not
Table1 Pressure and water discharge.

\begin{tabular}{|c|c|c|c|c|}
\hline Item & Pressure & Discharge & Average & Variance \\
\hline (Unit) & $(\mathrm{kPa})$ & $(1 / \mathrm{min})$ & $(\mathrm{ml} / \mathrm{min} / 0.5 \mathrm{~m})$ & $(\mathrm{ml} / \mathrm{min} / 0.5 \mathrm{~m})$ \\
\hline 1 & 31.4 & 1.8 & 13.9 & 47.7 \\
\hline 2 & 15.7 & 1.3 & 9.2 & 9.4 \\
\hline 3 & & 0.5 & 3.5 & 1.9 \\
\hline
\end{tabular}

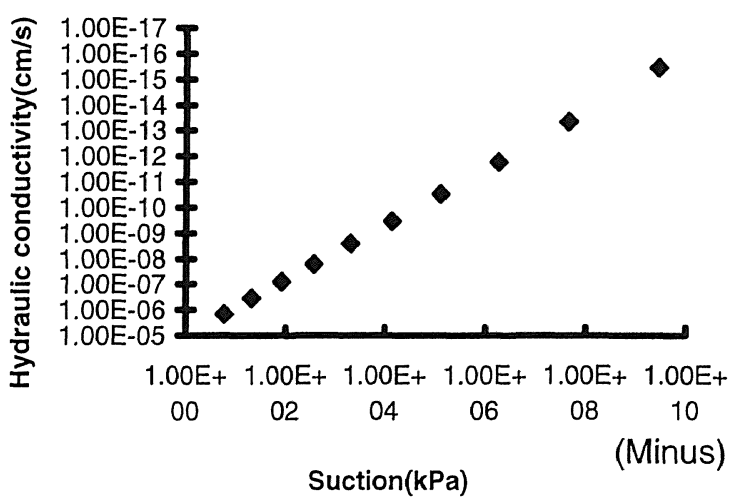

Fig.3 Relationship between hydraulic conductivity and suction 
The relationship between evaporation from the soil surface and soil water suction is shown in Fig.5. When there is abundant moisture, evaporation does not depend on soil texture. It decreases gradually when the soil dries to more than $100 \mathrm{kPa}$ 3) Extent of water movement. The infiltration water front of Kanto-loam is shown in Fig.6.

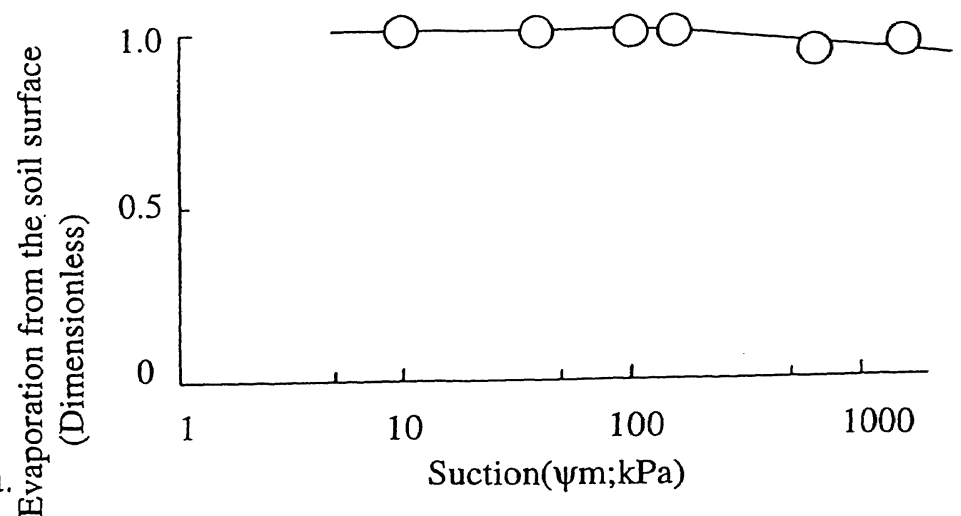

Fig.4 Relationship between suction and evaporation ffrom soil surface.

The infiltration front became somewhat oval at the bottom with time, at though the front almost extends spherically just after irrigation. The water front extended to about $0.25 \mathrm{~m}$ in diameter in about 2days after irrigation.

Simulated results are shown in Fig.7. They are in good agreement with observed data.

$\mathrm{q}=0.8(1 / 50 \mathrm{~m} / \mathrm{min})$

Unit(cm)
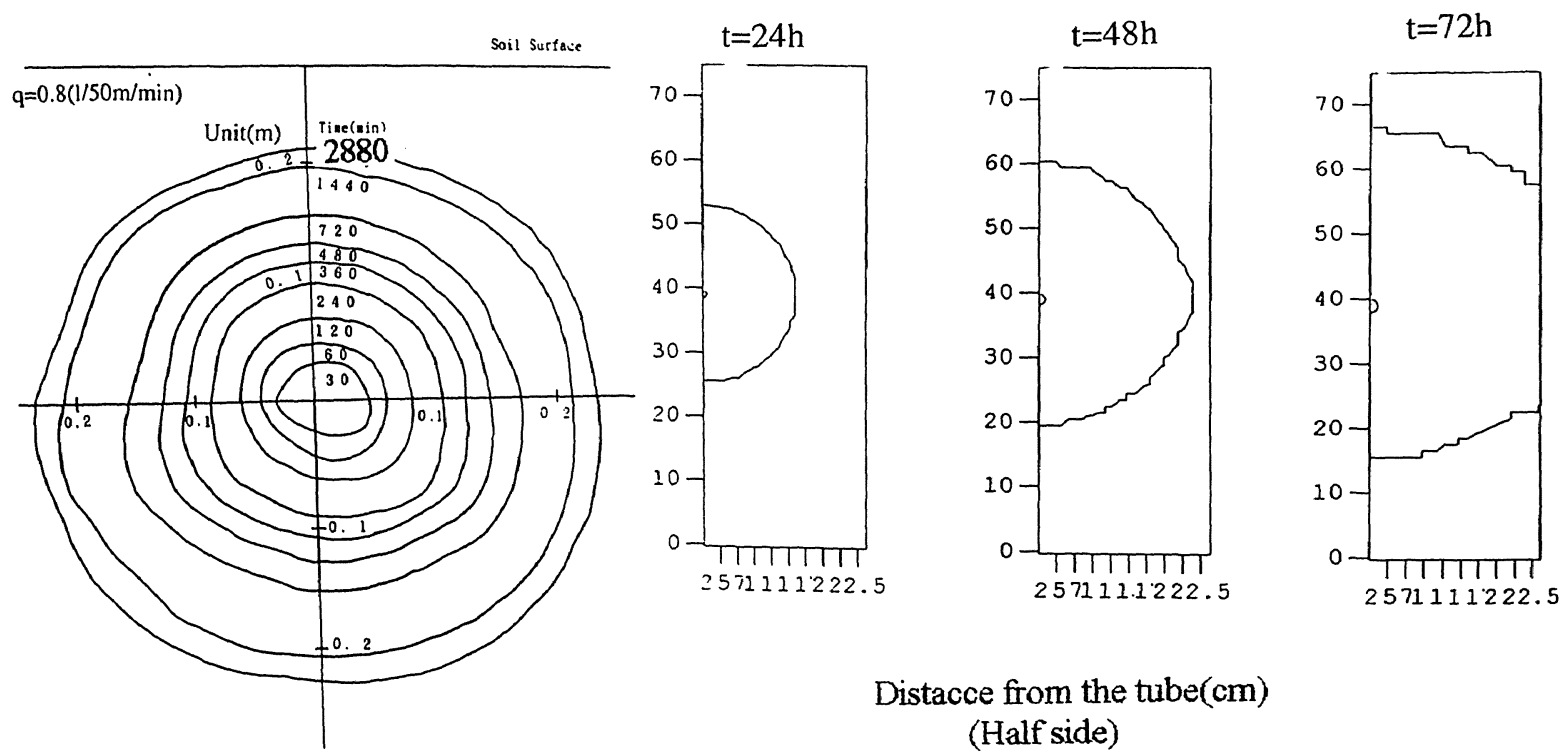

Distacce from the tube $(\mathrm{cm})$

(Half side)

Fig.5 Infiltration front from the tube. (Observed)

\section{Conclusion}

Fig.6 Infiltration front from the tube.

(Simulated)

Uniformity of water discharge from the tube was not fairly high. The water front extended to about $0.25 \mathrm{~m}$ in diameter after about 2days of irrigation in one Kantoloam. The model could predict the water front from the tube.

\section{Reference}

Bluce R. R. and Klute A.; The measurement of soil moisture diffusivity, Soil Sci.

Soc. Amer. Pro.,20,pp.458 462(1956) 